\title{
SPACE MEDICINE
}

$\mathrm{T}$ HE first symposium on space medicine to be held in Great Britain was held at B.M.A. House, London, on October 16 and 17. The symposium was organized by the British Interplanetary Society, and coincided with the twenty-fifth anniversary of its foundation. The symposium was arranged to discuss the reactions of man to the conditions that will be encountered in space and on other planets, and of the equipment that will be required for survival in these hostile environments. Those taking part were research workers in physiology, psychology and human engineering; and the term 'space medicine' embraces the application of these sciences to extraterrestrial environments.

It is certain that man will travel into space within a few years. His first venture will probably be in orbit, close to the Earth, and lasting a few hours. His second venture will be to the Moon, and his third to one of the planets. Voyages beyond our own solar system are difficult to comprehend, but should not be dismissed too lightly.

The reason for man travelling into space is a controversial subject. Some contend that he merely adds to the complexity of the space vehicle; others that he will earn his keep by taking decisions, particularly in the event of an unforseen emergency. The fact remains, however, that he will go, and that he will be faced with many of the problems discussed at the symposium.

The chairman of the British Interplanetary Society, Dr. L. R. Shepherd, opened the conference with a brief review of the major problems facing man in space, seen from the point of view of a physicist. Over the course of two days, fourteen papers were delivered, and covered fairly well the salient problems of space medicine.

The major physiological difference between travel in a space vehicle and some Earth-bound vehicle such as a submarine is the absence of the gravitational force. Dr. M. P. Lansberg, of the National Aeromedical Centre in Holland, discussed in his paper some consequences of weightlessness. In the absence of gravitational clues to position, some disorientation may occur, and motor activities will have to be re-learned. Complete immersion in water produces some of the characteristics of weightlessness, and a true state of free fall can be produced for periods of about half a minute by parabolic flight in an aircraft. It would be unwise to extrapolate from such flights to the condition of prolonged weightlessness because of the stresses which precede the parabolic flight and because of its short duration. Von Braun has proposed that the space vehicle should rotate, providing artificial weight for the occupants at its periphery. There are serious disadvantages to this system. Changes in weight would be experienced after moving closer to the centre of rotation and also when walking in the direction of rotation, or in the opposite direction, at a constant distance from the centre of rotation. Perhaps more serious, movement of the head would cause tilting and turning sensations, with their appropriate reactions, in the wrong planes. This is due to rotation of the semi-circular canals of the ear while under the influence of a centrifugal rather than a gravitational force.
Some disorientation would seem to be inevitable. Sqn. Ldr. T. C. D. Whiteside, of the R.A.F. Institute of Aviation Medicine at Farnborough, emphasized the importance of the oculogravic and oculogyric reflexes, and issued a warning on the possible seriousness of motion sickness.

Flt. Lt. J. C. Guignard, of the R.A.F. Institute of Aviation Medicine, considered that accelerations at multiples of $g$, lasting for several minutes, to which the astronaut will be exposed during a rocket take-off, are probably acceptable for a man aligned in the correct position. He concentrated on the physiological effects of transient mechanical forces. Noise and vibration levels are high in large rocket vehicles under power, and, during re-entry at orbital velocities, buffeting of a space vehicle would be poorly damped at the fringe of the atmosphere, and might induce vibrations and oscillatory flight patterns of sufficient intensity to prohibit the crew from controlling the descent. In space, there will be no damping, and any vibration must be absorbed by the vehicle and its occupants. Structure-borne oscillations at frequencies below $100 \mathrm{c} . / \mathrm{s}$. are a potential cause of discomfort, fatigue and impaired performance; and low-frequency shaking, below $10 \mathrm{c} . / \mathrm{s}$. is a serious nuisance and is difficult to isolate. Flt. Lt. Guignard doubted whether man would float about in an orbital space-suit con. structing a satellite from its component parts. If he did, the suit or capsule would have to be a massive affair incorporating gyroscopic stabilization to prevent undamped spin or tumble (which might be fatal), and whole-body harness and anti-shock packaging to save him from impact injuries in a collision.

Dr. H. Bjurstedt, of the Laboratory of Aviation and Naval Medicine at Stockholm, described the results of subjecting anæsthetized dogs to prolonged $g$ forces in the head-to-tail direction. $\mathrm{He}$ found hypoxæmia in spite of the fact that the animals were hyperventilating and breathing 100 per cent oxygen, and attributed this to disturbances of ventilation and perfusion in the lungs. It was not clear why there was present, also, a marked alkalosis.

Dr. C. J. Clemedson, of the Research Institute for National Defence in Stockholm, considered the relationship between his studies on blast injury in animals and the problem of explosive decompression in a space vehicle.

Commander G. W. Hoover led a team from the U.S. Office of Naval Research. He delivered a paper on the man-machine system in space vehicles. This consisted, in essence, of proposals for an integrated approach by all concerned to the problem of finding out under what conditions a man works most happily and efficiently in a closed vehicle. These conditions would then be specified for the space vehicle.

The American delegation was emphatic in demanding a cabin environment which did not subject the crew to any unnecessary physiological or psychological strain. Dr. G. Pugh, of the Medical Research Council, was also in favour of a comfortable environment, but pointed out that, as in the case of explorers of the past, the demand for reduction in weight and complexity might necessitate exploitation of man's capacity to adapt himself to a wide range of environmental stresses. He discussed the possibility of 
reducing metabolic rate and of breathing oxygen at low partial pressures to save weight in food and oxygen. Dr. Pugh also made the important point that while lack of preparation had been the undoing of many previous explorations, the ultimate test of performance is in the real situation.

Flt. Lt. J. Billingham, of the R.A.F. Institute of Aviation Medicine, examined the problems of heat exchange between man and the sealed cabin, and proposed a specification for environmental conditions during interplanetary flight. $\mathrm{He}$ also presented a paper on heat exchange between man, his pressure suit and the environment on the surface of the Moon.

Dr. K. F. Jackson, of the R.A.F. Institute of Aviation Medicine, read a paper on the impairment of human performance in control. He presented the results of an investigation into the factors affecting performance of the crews of long-range reconnaissance aircraft, with particular reference to fatigue. $\mathrm{H}_{\Theta}$ also demonstrated a portable version of his multiple tracking test apparatus, which provides measurements of about ten different aspects of performance.

Mr. C. Cunningham, from the Air Ministry, described the effects of sensory impoverishment, confinement and deprivation of sleep. If these are allowed to continue unchecked for a number of days, the result is changes in the personality and the intellect, often to a degree where logical thought and action become impossible. His evidence was obtained from experimental work, particularly that of Hebb, and from the experiences of former prisoners. There is no doubt that these factors will be of paramount importance in space travel, especially in the case of journeys lasting for years.

Dr. A. S. Parkes and Dr. Audrey V. Smith, of the National Institute for Medical Research, directed attention in their paper on the transport in space of life in the dried or frozen state to the considerable economy of carrying some of the crew of a space vehicle in a state of suspended animation. They considered, however, that the possibility of freezing man was remote. On the other hand, there should be less difficulty in landing spores and seeds on another planet.

Mr. S. W. F. Hanson, of the Ministry of Agriculture, discussed the very practical problems of feeding during travel in space, and the difficulties in the maintenance of a biological cycle, including plants, for journeys of long duration.

The final speaker was Dr. A. E. Slater, of the British Interplanetary Society, who must take credit for the organization of the symposium. He discussed the hazards to man of the radiation belt revealed by the Explorer satellites. A region of intense radiation exists between latitudes $30^{\circ} \mathrm{N}$. and $30^{\circ} \mathrm{S}$. of the magnetic equator. Singer attributed this belt to protons captured in the Earth's magnetic field, and his theory has received considerable support from the information received from the American rocket Pioneer, which showed the radiation to be maximal at an altitude of 5,70 miles. Dr. Slater concluded on an optimistic note, describing a suggestion by Singer that the radiation belt could be mopped up in one year by a satellite some ten metres in diameter travelling in an appropriate orbit. J. BILLINGHAM

\section{CHEMICAL PATHOLOGY OF THE NERVOUS SYSTEM}

$\mathrm{T}$ HE subject of the third International Neurochemical Symposium, which was held in the University of Strasbourg during August 25-29, was "The Chemical Pathology of the Nervous System". Several facets of this ramifying topic were discussed by experts from a number of countries, and as those attending the Symposium were restricted to a comparatively small number (130) there were often vigorous and satisfying discussions. As in previous similar symposia, the main subjects were subdivided so that there could be reviews followed by short individual papers on related topics.

A whole day was devoted to metabolic disorders, and the inborn errors of metabolism received detailed attention from Dr. G. A. Rose (London) and Dr. G. A. Jervis (New York). Dr. Rose described a new form of mental defect characterized by the excretion of arginosuccinic acid, and suggested that mental defect may, in fact, include a large group of metabolic diseases of which 'arginosuccinuria' is one, the biochemical lesion in this condition being the inability to split arginosuccinic acid into arginine and fumaric acid.

In this section, too, there were interesting papers on phenylketonuria and Hartnup's disease (Dr: R. Rodnight, London), and the subject of the cerebral lipidoses was also discussed. In connexion with cerebral lipidoses, Dr. M. Lees (Boston) pointed out that analytical methods suitable for normal brain tissue may not necessarily be applicable to pathological material. It was obvious, too, that much more precise information on the chemical nature of brain gangliosides and sulphatides is desirable if rapid progress is to be made in this field. Dr. H. M. Sinclair (Oxford), reviewing the subject of metabolic disorders of nutritional origin, emphasized the wide variety of dietary substances necessary for the adequate maintenance of a 'normal' nervous system.

Prof. J. M. Cumings (London), in a comprehensive review of the chemical pathology of copper, paid particular attention to the copper protein present in brain tissue and its possible significance. The chemical nature of cerebrocuprein in normal brain and that obtained from the brain of individuals suffering from Wilson's disease (hepatolenticular degeneration) was then discussed by Dr. H. Porter (Boston), who has found a significant difference in the chemical properties and electrophoretic mobilities of the two proteins. Members of the Symposium found this an exciting new observation.

The fact that a considerable number of biochemical investigations have been carried out on demyelination processes was reflected in a number of interesting papers on this topic. A review of demyelination in general was given by Dr. R. D. Adams (Boston), and a masterly and concise account of Wallerian degeneration by Prof. R. Rossiter (London, Canada) vividly demonstrated to the audience how precise chemical studies can be used to map a pathological process. Dr. E. Robins's (St. Louis) studies on the biochemistry of chromatolysis in individual anterior horn cells after axonal section illustrated the signifi- 